\title{
OS SIGNIFICADOS DO PROJETO ESPORTE CIDADÃO DE INDAIATUBA-SP PARA SEUS FREQUENTADORES
}

Recebido em: 10/02/2020

Aprovado em: 03/07/2020

Licença:@) (1) @

Luiz Guilherme Bergamo ${ }^{1}$

Centro Universitário Max Planck (UniMAX)

Indaiatuba - SP- Brasil

Cinthia Lopes da Silva ${ }^{2}$

Universidade Metodista de Piracicaba

Piracicaba - SP - Brasil

RESUMO: O presente estudo tem como objetivo verificar e analisar os significados das atividades esportivas e de lazer para frequentadores do Esporte Cidadão do município de Indaiatuba-SP. Como procedimento metodológico foi realizado pesquisa bibliográfica e de campo. $\mathrm{O}$ estudo tem um caráter qualitativo e quantitativo, sendo a pesquisa de campo realizada com os alunos do projeto que estão há mais de dois anos frequentando as aulas. As técnicas utilizadas na pesquisa foram entrevistas semiestruturadas, observação das atividades e conduta dos alunos e diário de campo. O projeto na visão dos sujeitos participantes oferece oportunidade para a socialização, competição e diversão. Com relação ao entendimento sobre lazer, os interesses mais vinculados pelos entrevistados, são os interesses sociais. Os significados que os alunos entrevistados atribuem às atividades do projeto se remetem à procura de relacionamentos, de querer socializar-se mais, buscar novas amizades, conseguir trabalhar em equipe e saber lidar com pessoas.

PALAVRAS-CHAVE: Atividades de Lazer. Educação. Cultura. Política Pública.

\section{THE MEANINGS OF THE CITIZEN SPORTS PROJECT OF INDAIATUBA-SP FOR ITS PARTICIPANTS}

\footnotetext{
${ }^{1}$ Graduado em Educação Física pela PUC Campinas, Mestre em Ciências do Movimento Humano pela Universidade Metodista de Piracicaba-SP (UNIMEP). Docente dos cursos de Licenciatura e Bacharelado em Educação Física no Centro Universitário Max Planck (UniMAX) em Indaiatuba-SP e servidor público da Prefeitura Municipal de Indaiatuba-SP. Membro do Grupo de Estudo e Pesquisa em Lazer, Práticas Corporais e Cultura - GELC/ CNPq.

${ }^{2}$ Cinthia Lopes da Silva é graduada, mestre e doutora em Educação Física pela UNICAMP, com doutorado sanduíche na Universidade Técnica de Lisboa (Portugal). Tem pós-doutorado na área de Comunicação pela Universitat Pompeu Fabra (Espanha). É docente na Universidade Metodista de Piracicaba (UNIMEP) desde 2008 com vínculo no Programa de Pós-graduação em Ciências do Movimento Humano. Coordena o Grupo de Estudo e Pesquisa em Lazer, Práticas Corporais e Cultura (GELC)/CNPq e é membro fundadora da ANPEL.
} 


\begin{abstract}
This study aims to verify and analyze the meanings of sports and leisure activities to goers of the Citizen Sport Project in the municipality of Indaiatuba city. As a methodological procedure, bibliographic and field research was carried out. The study has a qualitative and quantitative character, and the field research was carried out with the students of the project who have been attending classes for more than two years. The techniques used in the research were semi-structured interviews, observation of the activities and students conduct and field diary. The project in the view of the participating subjects offers an opportunity for socialization, competition and fun. Regarding the understanding of leisure, the interests most linked by the interviewees are social interests. The meanings that the interviewed students attribute to the activities of the project refer to the search for relationships, to want to socialize more, to seek new friendships, to be able to work in a team and to know how to deal with people.
\end{abstract}

KEYWORDS: Leisure Activities. Education. Culture. Public Policy.

\title{
Introdução
}

O esporte é um dos elementos da cultura preferidos pelos praticantes e tido como um dos principais conteúdos nas atividades do projeto Esporte Cidadão de Indaiatuba-SP. No contexto do lazer, o esporte é também presente no cotidiano da maioria das atividades dos alunos, sendo parte dos interesses físicoesportivos do lazer (VELOZO, 2009). Assim, quais os significados das atividades esportivas e de lazer do Projeto Esporte Cidadão de Indaiatuba para seus frequentadores? Identificar e analisar essa pergunta é o objetivo dessa investigação.

Durante 11 meses por ano, aproximadamente 7000 crianças e adolescentes do município de Indaiatuba-SP têm participado de diversas modalidades coletivas e individuais em aulas realizadas duas vezes por semana e com duração de uma hora cada, promovidas pelo Projeto Esporte Cidadão que atende crianças de 6 anos até adolescentes de 15 anos. Esse projeto é desenvolvido pela Prefeitura do município de Indaiatuba-SP via sua Secretaria de Esportes. No projeto estão envolvidos 31 professores, 4 coordenadores de área, um coordenador pedagógico e um coordenador geral que são os responsáveis pelo desenvolvimento dos projetos de esporte e lazer. 
O projeto esportivo e de lazer acontece no contraturno das aulas, ou seja, após as obrigações escolares em 18 (dezoito) núcleos esportivos espalhados pelo município. O projeto contempla 18 (dezoito) modalidades esportivas, tais como: atletismo, basquetebol, beisebol, bicicross, capoeira, caratê, futebol, futsal, ginástica artística, ginástica rítmica, ginástica de trampolim, handebol, jiu-jitsu, judô, natação, taekwondo, tênis e voleibol. Essas modalidades não estão em todos os núcleos esportivos, elas se distribuem ao longo da cidade, mediante a estrutura e demanda dos bairros. Por exemplo, modalidades como futebol, futsal e natação são bem procuradas e estão em seis núcleos, enquanto os demais núcleos absorvem as outras modalidades, como as ginásticas e lutas que precisam de um lugar específico para a prática.

Para compreender o esporte como fenômeno cultural da sociedade contemporânea, há a necessidade de buscar entender como tal elemento se insere na vida dos sujeitos, que valores, sentidos e significados são atribuídos ao esporte pelos sujeitos envolvidos. Assim, considera-se de modo inicial que as crianças/jovens que frequentam as atividades de esporte e lazer do Projeto Esporte Cidadão se relacionam e se expressam de certo modo e atribuem um conjunto de significados às práticas realizadas no Projeto. Assim, a pesquisa gerará novos conhecimentos a partir dos instrumentos selecionados para a investigação, de modo a se conhecer melhor os significados do projeto para seus frequentadores e também como uma política pública proposta.

\section{Método}

O estudo tem um caráter qualitativo, para Minayo (1994, p.22) esse tipo de estudo “(...) trabalha com o universo dos significados, dos motivos, das aspirações, das crenças, dos valores e das atitudes". 
O procedimento metodológico utilizado foi a pesquisa bibliográfica e de campo. Na pesquisa bibliográfica, primeira fase da investigação, foram utilizadas as técnicas de análise textual, temática, interpretativa, problematização e síntese pessoal, de acordo com Severino (2007). Foi efetuado levantamento bibliográfico nos Sistemas de bibliotecas da Universidade Metodista de Piracicaba (UNIMEP) e da Universidade Estadual de Campinas (UNICAMP), no banco de Teses e dissertações da Capes, Scielo, Portal de Periódicos Capes e as Revistas especializadas como Movimento, Licere, Pensar a Prática e Brasileira de Ciência e Movimento. A estratégia de busca nas bases foi a partir do termo “projetos de esportes e lazer”, utilizando as palavras-chave: lazer, esporte educacional, cultura, políticas públicas e projetos de esportes e lazer, de forma combinada e não combinada.

A segunda fase da investigação consistiu na pesquisa de campo, aprovada pelo Comitê de Ética de Pesquisa em seres humanos da Universidade Metodista de Piracicaba (CEP - UNIMEP), com número do CAAE 95904318.8.0000.5507/2018, em que todos os sujeitos envolvidos na pesquisa assinaram o Termo de Consentimento Livre e Esclarecido. Essa fase de investigação teve o objetivo de identificação e análise dos significados do projeto Esporte Cidadão do município de Indaiatuba/SP para os alunos frequentadores.

Foi escolhido o Centro Esportivo do Trabalhador (CET), por se tratar do maior núcleo esportivo do projeto Esporte Cidadão em número de alunos e professores envolvidos. O início do nosso contato com os entrevistados ocorreu da seguinte maneira: chegando ao núcleo esportivo Centro Esportivo do Trabalhador (CET), procuramos o coordenador do local, que logo nos encaminhou aos professores responsáveis pelas turmas do projeto Esporte Cidadão. Com estes, fizemos uma reunião para apresentar o projeto de pesquisa e estabelecer como seria o contato com os pais e alunos. 
Os professores que tivemos a reunião estão trabalhando há mais de quatro anos no local e no projeto, e através da consulta à lista de chamada, nos indicaram os alunos que estariam dentro dos critérios para as entrevistas, ou seja, que estão matriculados e frequentando as aulas do projeto há mais de dois anos e com idade entre 12 a 15 anos. A escolha dessa faixa etária foi por não depender tanto dos pais ou responsáveis para expressar suas opiniões, responder os questionários, além da maioria dos pais/responsáveis não estarem presentes nas aulas.

Dos 40 alunos convidados para pesquisa (20 meninos e 20 meninas), 34 alunos (17 meninos e 17 meninas) aceitaram e assinaram os termos para a realização das entrevistas, que foram gravadas e transcritas posteriormente. Iremos utilizar a numeração de 1 a 34 para identificar os entrevistados para manter o sigilo dos entrevistados. $\mathrm{O}$ fator determinante para a escolha desse número de entrevistados foram os estudos de Duarte (2002). Os números de entrevistados foram definidos por saturação de dados, com o número mínimo de trinta e quatro entrevistados, sendo assim divididos: dezessete meninos e dezessete meninas participantes do projeto de esporte e lazer - Esporte Cidadão da cidade de Indaiatuba-SP.

Durante os meses de agosto, setembro e outubro de 2019 estivemos no núcleo esportivo CET para a realização da pesquisa campo. Esta etapa consistiu nas entrevistas e a observação das atividades e condutas dos alunos antes, durante e após as aulas. Os pontos observados foram descritos em diário de campo.

Os espaços que compõem o núcleo esportivo (CET) oferecido para as aulas do projeto são duas quadras poliesportivas cobertas, três quadras de areia, três quadras de peteca cobertas, dois campos de futebol, uma pista de atletismo, três piscinas (uma recreativa, uma de 25 metros coberta e uma de 50 metros coberta. 
Como instrumento de coleta dos dados foi utilizado um gravador, para gravação de voz durante as entrevistas. Foi utilizada a entrevista semiestruturada contendo as seguintes perguntas: 1) Quais as práticas esportivas você já participou no Projeto Esporte Cidadão? 2) O que é esporte para você ? 3) Como você vê o esporte dentro do projeto? 4) O que é lazer para você? 5) Você vivenciou experiências de lazer em anos anteriores ao Projeto Esporte Cidadão? 6) Além de praticar esporte tem outra forma de vivenciar o lazer? 7) O que significa para você as atividades de esporte e de lazer no Projeto Esporte Cidadão? 8) O que faz com que você participe/permaneça no Projeto?

A terceira fase consistiu nas análises dos dados coletados na pesquisa de campo. A finalidade dessa etapa da pesquisa é de interpretar as respostas dos alunos frequentadores do Projeto Esporte Cidadão da cidade de Indaiatuba-SP dadas nas entrevistas, assim como interpretar as observações realizadas e anotadas no diário de campo. A partir desses instrumentos de pesquisa procedemos ao nível da investigação da compreensão e do comportamento social em relação aos significados atribuídos às práticas das atividades de esporte e de lazer para os sujeitos entrevistados, para isso tivemos inspiração em Minayo (1994) e Geertz (1989). Para o aprofundamento nesses significados identificados na investigação foi realizado o diálogo com a literatura, utilizando os textos identificados na primeira fase da investigação.

\section{Resultados e Discussão}

Apresentaremos a seguir os entrevistados, assim como os resultados e discussões. Em um quadro detalharemos os entrevistados, numeração dada, gênero, idade e quanto tempo estão matriculados nas aulas do projeto. Não consideramos os resultados sobre o fator gênero, porque não foram identificadas diferenças significativas entre os gêneros masculino e feminino nos discursos analisados. 
Os Significados do Projeto Esporte Cidadão de Indaiatuba-SP para seus Frequentadores Luiz Guilherme Bergamo e Cinthia Lopes da Silva

Gráfico 1 - Detalhes dos sujeitos masculinos entrevistados do projeto Esporte Cidadão

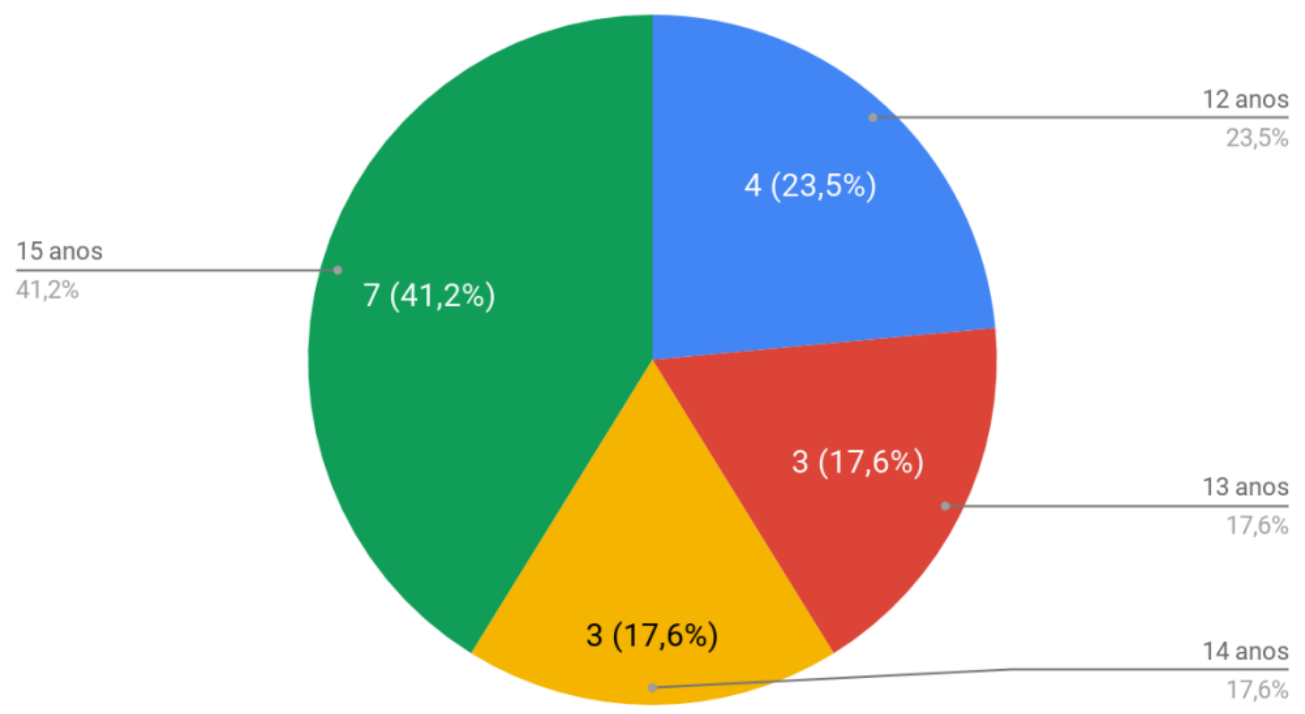

Gráfico 2 - Detalhes dos sujeitos femininos entrevistados do projeto Esporte Cidadão

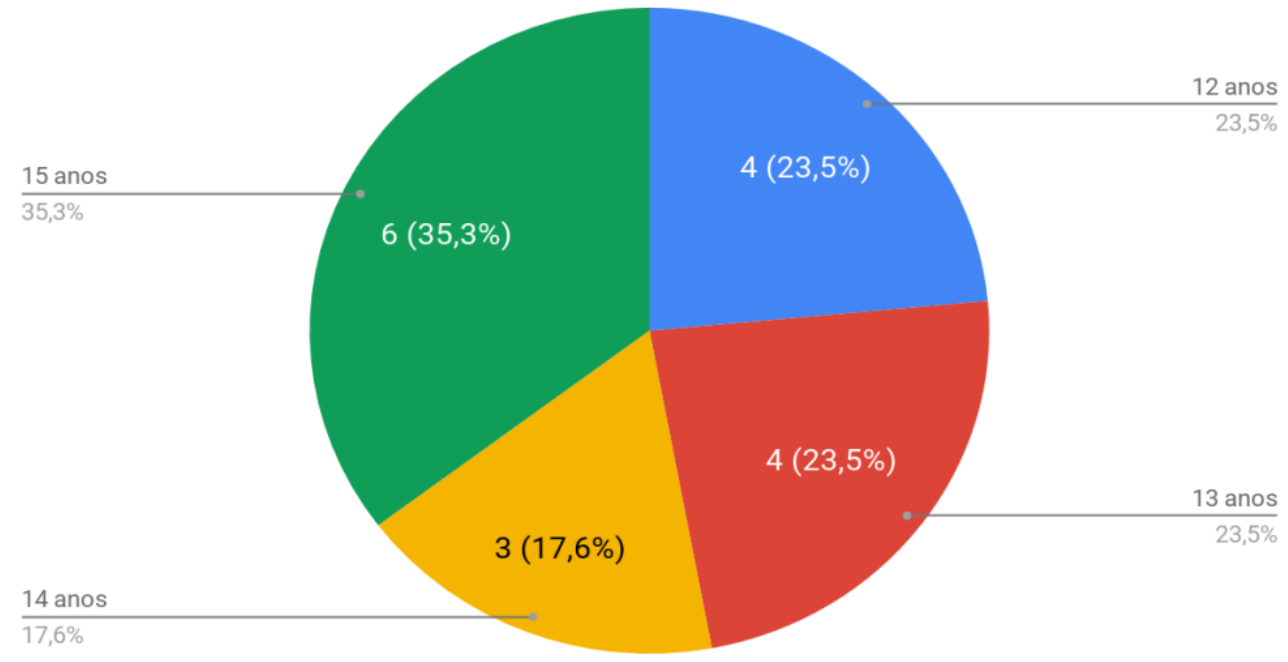

Dos entrevistados, oito alunos têm 12 anos de idade, sete tem 13 anos, seis tem 14 anos e treze tem 15 anos de idade, gerando uma média de 13 anos e meio de idade.

As respostas dadas a primeira questão - "quais as práticas esportivas você já participou no projeto Esporte Cidadão?" - foram bem diversificadas, e os entrevistados mencionam mais de uma prática, como vôlei, natação, basquete, atletismo, handebol, futebol e futsal. 
O vôlei foi citado por 25 diferentes entrevistados, enquanto a natação por 22 e basquete por 15 nas modalidades mais citadas. As modalidades menos citadas (não estão no gráfico) foram o tênis, tênis de mesa e bicicross pelo entrevistado 5, assim como a ginástica artística (entrevistada 16), o caratê (entrevistado 23) e o taekwondo (entrevistado 28) que foram citados uma única vez pelos entrevistados.

As práticas esportivas mais citadas foram as modalidades que ocorrem no projeto no CET há mais tempo, assim como a dificuldade para obter a vaga de natação que é a mais concorrida no projeto. A modalidade vôlei é bem procurada na faixa etária dos adolescentes, e o professor dessa modalidade é o que está há mais tempo no local.

Os alunos citam o professor de vôlei em diversos momentos das entrevistas como um dos fatores que os motivam a frequentar e participar das aulas do projeto, como podemos observar nas respostas a seguir.

As atividades do projeto são bem conduzidas pelo professor, faz a gente se sentir seguro, e a gente pode sempre contar com ele, aqui a gente se sente em casa (Entrevistado 30).

Gosto muito do vôlei e principalmente do professor, pois ele sempre me incentivou, nos ajuda quando eu não estava conseguindo realizar os fundamentos do vôlei (Entrevistada 12).

Eu gosto muito do vôlei, do meu professor, ele dá muito bem às aulas, consegue fazer com que todo mundo, independente se você chegou aqui hoje, ou eu que estou aqui há quatro anos, ele consegue que todo mundo tire o máximo do proveito das aulas (Entrevistada 29).

Podemos observar a influência que o professor tem sobre seus alunos, as relações entre o professor e o aluno que determinam a sua permanência nas atividades do projeto. O professor possui um papel importante nesse processo, o qual os alunos se apegam como mencionado pelo entrevistado 30, e os têm como referência de liderança, de afetividade (mencionado pela entrevistada 12) e de conseguir extrair o melhor de todos (mencionado pela entrevistada 29). Por outro lado, percebe-se que os entrevistados que citaram práticas esportivas como o bicicross, tênis e tênis de mesa (entrevistado 5), ginástica artística 
(entrevistada 16), caratê (entrevistado 23) e taekwondo (entrevistado 28) trocaram uma modalidade individual por uma modalidade coletiva em busca de maior socialização, conforme podemos observar nas respostas abaixo:

\footnotetext{
Vim em busca de me socializar com outras pessoas, eu conheci novas pessoas dentro do basquete e aprendo novas coisas dos esportes (Entrevistado 5).

$\mathrm{O}$ vôlei me ajudou a me relacionar com as pessoas, a interagir com elas. No vôlei eu jogo com eles, eu vivencio algo com eles, nesse esporte precisamos de mais gente para jogar (Entrevistada 16)

Sempre fui ansioso, deixei de ser egoísta fazendo o basquete (Entrevistado 23)

Antes do vôlei eu era muito tímido, e aqui comecei a me envolver com as pessoas daqui, a fazer novas amizades e melhorei muito a minha timidez (Entrevistado 28).
}

Podemos observar nas respostas dos alunos que possivelmente eles tiveram outras influências culturais que foram determinantes em suas experiências para que tivessem um histórico de práticas corporais não tão tradicionais.

Além do lazer, outro elemento da cultura e que tem grande relação com as diversas estruturas sociais é o esporte que ganhou outra dimensão a partir do século XX e se antes estava restrito a parcelas específicas da população, ao longo desse período se tornou acessível às massas. $\mathrm{O}$ esporte conquistou popularidade e, hoje, se trata de um fenômeno social que impacta a vida cotidiana. De acordo com Ronaldo Helal, em seu livro $O$ que é sociologia do Esporte (1990), o esporte é uma das instituições sociais mais sólidas do mundo moderno.

Segundo Helal (1990), para compreender o esporte de maneira sociológica, o primeiro passo é encará-lo como um fato social, algo externo ao indivíduo, investido com uma função coercitiva na sociedade. O segundo passo é distinguir três atividades que, de certa maneira, se assemelham e se inter-relacionam. São elas: brincadeira, jogo e esporte. A primeira é constituída por espontaneidade, criatividade, improvisação, liberdade de ação e controle da própria atividade, conforme estudado pela sociologia do esporte. 
Quando a brincadeira se torna mais séria, ou seja, com regras fixas, como é o caso do jogo, os elementos como espontaneidade, criatividade, improvisação são "perdidos" ou até mesmo deixam de existir, uma vez que há regras estabelecidas para o jogo. A segunda pode ser considerada como uma brincadeira com sistematização de regras fixas, ou seja, sempre que a brincadeira começa a estipular regras para a sua prática, ela se transforma em jogo. Por último, o esporte pode ser tratado como um jogo com submissão a uma organização burocrática mais ampla, que vai além dos interesses individuais dos jogadores. Podemos considerar que essa é uma classificação na tentativa de diferenciar a brincadeira, o jogo e o esporte, no entanto, consideramos a necessidade de relativizar essa classificação, já que a espontaneidade, a criatividade e a improvisação são qualidades que podem estar presentes nas três atividades (brincadeira, jogo e esporte).

Na segunda pergunta "O que é esporte para você?" as respostas foram variadas e observamos que os alunos entrevistados falam sobre os vários significados do esporte para eles. Discursos como: "esporte significa saúde” (23 alunos, sendo 11 meninos e 12 meninas), “esporte é um tipo de lazer” (12 alunos, sendo 7 meninos e 5 meninas), “esporte é e traz felicidade" (8 alunos, sendo 4 meninos e 4 meninas), "esporte é uma forma de competição" (6 alunos, sendo 3 meninos e 3 meninas), "esporte proporciona trabalho em equipe" (4 alunos, sendo 2 meninos e 2 meninas), "esporte proporciona oportunidades" (3 alunos, sendo 1 menino e 2 meninas), “esporte gera desenvolvimento" (3 alunos, sendo 2 meninos e 1 menina), "esporte melhora o raciocínio" (Entrevistado 1) e "esporte ajuda eu aprender valores" (Entrevistada 8).

Esses significados indicam que os alunos não mencionam, em princípio, o interesse na prática do esporte em si, ao menos não falam sobre isso diretamente, mas dentre esses significados há uma visão funcionalista (como melhorar o raciocínio, proporcionar oportunidades, o esporte gera desenvolvimento), mas há também uma visão 
que indica a construção de valores sociais que podem ser revolucionários como o trabalho em equipe, os valores que o esporte proporciona que é a competição, mas a necessidade de se ter cooperação também.

Com relação a esses significados atribuídos ao esporte e às atividades do projeto podemos exemplificar alguns depoimentos dos alunos entrevistados.

Aqui além de jogar o esporte, a gente aprende valores morais, toda semana a professora fala com a gente sobre isso, assuntos sobre o mundo, poluição, meio ambiente, saúde, violência, segurança, educação, o que significa cada coisa (Entrevistado 23).

As atividades do projeto são boas porque é uma possibilidade para os jovens em fazer alguma coisa, a não estar nas ruas fazendo outras coisas, como crimes, por exemplo, e com as práticas esportivas todos podem ter discernimento e disciplina (Entrevistado 26).

Percebe-se nesses discursos, que o acesso dos sujeitos ao esporte os leva ao aprendizado de valores e conhecimentos como a resposta do entrevistado 23 , mas também há um entendimento de que o esporte tira os jovens da rua (entrevistado 26), por dar uma ocupação a eles, discurso esse muito comum no meio político e na mídia que restringe a visão de esporte como forma de conhecimento ou de interesse na modalidade praticada para ter uma justificativa que considera que o esporte por si só pode resolver problemas sociais.

Outras respostas dadas durante as entrevistas é de que o esporte vivenciado no projeto ou fora dele, independentemente do tipo de manifestação, não se restringe apenas a melhoria da saúde, mas sim gera possibilidades de crescimento pessoal, social e intelectual. Para exemplificar como tal fato se explica, durante as aulas, os alunos demonstram aprimoramento das técnicas e táticas do jogo, boa leitura do jogo, respeito ao próximo, além de outras capacidades observadas, ou seja, eles aprendem mais do que falam que aprendem, aprendem também sobre a prática em si.

Outra característica interessante é o fato de uma minoria dos entrevistados relacionar o esporte a novas oportunidades, auxílio no desenvolvimento, melhora do 
raciocínio e ajuda para aprender valores. Esses discursos apontam para uma das funções do lazer de desenvolvimento, o que vai ao encontro dos estudos de Marcellino (2001, p. 37), que por sua vez tem como base o autor francês Joffre Dumazedier, e considera que “a relação que se estabelece entre lazer e sociedade é dialética, ou seja, a mesma sociedade que o gerou, e exerce influências sobre o seu desenvolvimento, também pode ser por ele questionada, na vivência de seus valores".

Observa-se, então, que as percepções dos entrevistados em um primeiro momento são influenciadas por uma visão homogênea quando em suas falas propõem-se a explicar o fenômeno. No entanto, quando confrontamos suas respostas e suas experiências reveladas durante a entrevista, nota-se que o esporte para esses sujeitos tem vários outros significados como o convívio com o outro.

Eu gosto muito do vôlei e dos esportes do projeto. Todo ser humano precisa estar com alguém, ter um relacionamento para conseguir viver e, com isso, melhorar a qualidade de vida (Entrevistada 9).

Essa distinção entre o entendimento do que é esporte para os entrevistados nos remeteu a terceira pergunta da pesquisa: “Como você vê o esporte dentro do projeto?", tivemos várias respostas distintas. Uma boa parte dos participantes da pesquisa disse que é "uma oportunidade de conhecer novas pessoas e fazer novas amizades" (sendo seis entrevistados 5, 10, 21, 28, 30, 34, e cinco entrevistadas 7, 8, 12, 27 e 32). Sobre o discurso dos onze entrevistados podemos destacar algumas respostas:

Eu criei um laço de relacionamento com as pessoas, e isso me ajudou muito a entender o vôlei. A gente cria laços de amizades, a gente ganha confiança nas pessoas, é melhor de fazer as coisas (Entrevistada 8).

O grupo das aulas é muito unido, sempre faço muitos amigos" (Entrevistada 27).

Eu conheço novas pessoas, você consegue socializar com eles e fica feliz enquanto joga (Entrevistado 30).

As atividades são bem legais, estamos sempre interagindo com pessoas novas, podendo ajudar, conhecendo pessoas novas (Entrevistada 32). 
"Conhecer novas pessoas", "conseguir socializar-se" e "criar laços de relacionamento", "fazer amigos", foram respostas dos entrevistados 8, 27, 30 e 32, demonstrando como o esporte pode contribuir para o desenvolvimento das pessoas na esfera social. O esporte é considerado um fenômeno social e para Tubino (1999) “é uma atividade abrangente, visto que engloba diversas áreas importantes para a humanidade, como saúde, educação, turismo, entre outros”. É importante destacar também o papel social que o esporte desempenha na vida da humanidade, ou seja, a prática do esporte envolve a aquisição de habilidades físicas e sociais, valores, conhecimentos, atitudes e normas. O autor enfatiza que "o esporte é uma forma de sociabilização e de transmissão de valores". Portanto, observa-se que o esporte envolve todas as camadas, sendo um fenômeno que possui uma linguagem universal.

Outras respostas interessantes estão no discurso de nove entrevistados que disseram que "o esporte é uma oportunidade para as pessoas" (sendo cinco entrevistados $1,2,13,20,26$, e quatro entrevistadas $15,19,31$ e 33$)$. Dentre as respostas destacamos a seguir.

\footnotetext{
O esporte no projeto é muito importante, essa é uma grande chance de pessoas com menos oportunidades de praticar um esporte, sem importar com classe social (Entrevistado 13).

As atividades do projeto dão oportunidade para os jovens que querem se tornar um atleta no futuro (Entrevistada 15).

O esporte dentro do projeto é importante por que dá muitas oportunidades para outras pessoas (Entrevistado 20).
}

Percebe-se que há um olhar dos alunos que já frequentam as atividades do projeto com relação àqueles que ainda não fazem parte. A palavra "oportunidade" é enfatizada diversas vezes no discurso dos entrevistados, e isso nos traz elementos importantes para nossa discussão. 
A importância da oportunidade está relacionada às condições para esse acesso de uma forma geral e, para Marcellino (2001, p. 9), "existem barreiras interclasses e intraclasses sociais formando um todo inibidor que dificulta o acesso ao lazer, não só quantitativamente, mas, sobretudo qualitativamente", ou seja, tornam-se importantes a criação e consolidação de políticas públicas nas diversas comunidades brasileiras, que precisam ter esse olhar democrático.

Ainda com relação a esse tópico do esporte como oportunidade para as outras pessoas, destacamos uma resposta diferente a seguir.

\footnotetext{
A importância do esporte dentro do projeto é muito grande porque podemos ver muitos jovens interessados e quando participam acabam gostando e em vez de ficar na rua, fazendo outras coisas, como praticando crimes, por exemplo, com o esporte eles podem ter disciplina e discernimento (Entrevistado 26).
}

Esse discurso traz novamente elementos importantes para a nossa discussão. Um deles é o discurso muito forte existente em nosso contexto social, a ideia de que o esporte é a solução para os problemas sociais, de que por meio do esporte podemos solucionar os problemas da sociedade, sendo que na maioria das vezes esse discurso é isolado, não se pensam no conjunto de políticas públicas e ações necessárias para que as pessoas saiam das ruas, tenham uma vida digna, com trabalho, moradia, educação, saúde. O esporte é colocado como a única variante que pode resolver um problema que é maior e envolve vários setores das políticas públicas.

Por outro lado, os entrevistados 13, 22, 34 e as entrevistadas 16, 18 e 29, veem o esporte como uma "oportunidade de trabalhar em equipe". Para esses seis entrevistados o esporte tem um significado de interação, socialização, de trocas e aprendizado em equipe, como podemos perceber em algumas respostas a seguir.

No esporte é importante você ter a equipe inteira e saber trabalhar em equipe (Entrevistada 16). 
O projeto é importante, pois ensina a gente a trabalhar em equipe, esporte é isso, é oferecer isso para nós (Entrevistada 18).

O basquete me ajuda muito, porque ele é um esporte coletivo, faz a gente trabalhar em equipe e incentiva a gente ficar sempre em equipe (Entrevistado 22).

As atividades do projeto contribuem muito para conscientizar as pessoas para o trabalho em equipe, conhecer novas pessoas (Entrevistado 34).

Nas observações realizadas das aulas, "trabalhar em equipe" é algo que chamou a atenção dos alunos nas aulas do Projeto Esporte Cidadão, sendo algo expresso por eles. Ao recepcionar um aluno novo, contribuir no aquecimento em grupos e principalmente nos jogos realizados, a relação com o outro foi notada como elemento importante para a participação dos sujeitos no Projeto Esporte Cidadão.

A resposta "oportunidade de conhecer novos esportes" foi mencionada pelos entrevistados 4 e 23, e as entrevistadas 18, 31 e 33, conforme os discursos a seguir.

O projeto é importante porque possibilita a oportunidade para as pessoas conhecerem novos esportes (Entrevistada 18).

Aqui no projeto eu conheci muitos esportes, mais de seis, isso é importante porque podemos aprender sempre e escolher o que mais nos agrada (Entrevistado 23).

As atividades do projeto dão a oportunidade para os alunos a se identificarem com um esporte e conhecer outros (Entrevistada 31).

Nota-se que no núcleo Centro Esportivo do Trabalhador (CET) ocorrem várias atividades de esporte e lazer ao mesmo tempo. Enquanto os alunos aguardam o início das aulas ou até mesmo quando as realizam, é possível perceberem as atividades que estão correndo nas outras aulas. Conversando informalmente com os professores, eles disseram que os alunos têm a possibilidade de participar de até seis modalidades esportivas e que os alunos entrevistados já realizaram ao menos mais de uma modalidade esportiva no projeto.

Ao perguntarmos sobre o conceito de lazer, notamos que muitos deles relacionam o lazer à “diversão", “descanso", "tempo livre”, "ao prazer de sair com família e amigos”. 
Outros arriscaram uma definição como: "uma brincadeira sem regras", outros confundiram a definição do lazer com o esporte.

Nas falas dos sujeitos fica evidente a percepção deles em relação ao que compreendem sobre lazer, citam diversos interesses do lazer, como podemos observar nas falas a seguir.

Lazer é um tempo livre em que posso fazer várias coisas, como passeios, sair com a família e ir a parques (Entrevistada 3).

Lazer pra mim é diversão em família, algo que não tem muitas regras e eu posso decidir o que fazer (Entrevistado 11).

Lazer é momento em família, tempo de descanso, passeio em família e ir à igreja (Entrevistada 18).

O interesse social predomina em suas falas, o divertimento (citado 21 vezes, sendo por onze entrevistados $(4,10,11,13,20,21,22,25,28,30$ e 34) e dez entrevistadas (7, $8,9,14,15,17,24,27,31$ e 33 ) e o prazer de estar com familiares, foi citado 11 vezes, sendo por cinco entrevistados $(2,11,13,21$ e 26$)$ e seis entrevistadas $(7,9,18,19,24$ e 29) e estar com os amigos (citado sete vezes, sendo por quatro entrevistados $(1,5,22 \mathrm{e}$ 26) e três entrevistadas $(8,29$ e 33), foram elementos presentes nas respostas dos sujeitos. Os amigos nessa faixa etária da adolescência são muito importantes, é a fase da comunicação com o outro, e esse outro não é o pai, não é a mãe ou o tio, são seus colegas da mesma faixa etária que falam sua língua, que leem, que ouvem e que percebem o mundo de forma similar.

Podemos notar que a referência que os entrevistados têm do lazer está relacionada também com o conteúdo físicoesportivo do lazer - praticar esporte, citado 13 vezes, sendo por oito entrevistados $(2,10,13,21,22,23,26$ e 28$)$ e cinco entrevistadas $(14,19,24,27$ e 32), conforme descrito em alguns discursos a seguir.

Lazer pra mim é jogar basquete, andar de bicicleta, fazer uma caminhada no parque (Entrevistado 10). 
Quando tenho tempo livre eu jogo vôlei com os amigos para relaxar um pouco, dou uma caminhada no parque (Entrevistado 13).

Lazer é um tempo de andar de bicicleta, inclusive já fiz várias trilhas de bicicleta com meus amigos (Entrevistado 28).

Durante as aulas do projeto observou-se que a maneira como eles jogam está relacionada à forma como compreendem o esporte e o lazer. Existe o compromisso das atividades do projeto, no entanto, no momento do jogo os alunos se sentem "livres" para jogar à sua maneira, quebrando a rigidez característica do esporte de alto rendimento, ou seja, pelo que observamos e pelo que os alunos relataram, há a ressignificação da modalidade esporte e, portanto, a produção cultural por parte dos mesmos.

A questão tempo e atitude como parte inicial para compreendermos o lazer, e a satisfação pela prática vivenciada podemos perceber em algumas das falas, principalmente do sujeito entrevistado 29.

Lazer pra mim é fazer alguma coisa que goste no seu tempo livre, jogar vôlei, passear com os amigos, com a família, ler um livro, ficar na internet ou relaxar, algo do tipo que você tenha satisfação (Entrevistada 29).

A entrevistada refere-se à livre escolha da prática, e quando fala da prática do vôlei, da leitura, da internet, menciona alguns dos conteúdos do lazer, como o físicoesportivo, o intelectual, o virtual e a satisfação pela prática vivenciada.

Para Marcellino (2000, p. 8), o lazer considerado atitude será caracterizado pelo tipo de relação verificada entre o sujeito e a experiência vivida, basicamente provocada pela atividade. Ainda segundo o autor, o lazer ligado ao aspecto tempo, considera as atividades desenvolvidas no "tempo livre", não só das obrigações profissionais, mas também das familiares, sociais e religiosas. Com relação aos interesses práticos/manuais um aluno traz um discurso diferente relatado a seguir.

Moro em chácara, e lá tem muitas coisas, gosto de montar e desmontar coisas, tenho várias ferramentas lá, fico sempre arranjando coisas para fazer. Eu já até criei e montei uma rede adaptada de vôlei para eu jogar com os amigos quando eles vêm em casa (Entrevistado 22). 
Os interesses manuais são caracterizados, segundo Marcellino (2012), "pela manipulação no sentido de criar ou transformar objetos e materiais. Soma-se ainda o manuseio de locais, de espaços". Ainda segundo o autor, "os esportes podem ser entendidos e praticados como possibilidades de criação, recriação e adaptação de espaços e materiais". A partir das características ditas oficiais das modalidades esportivas, o interesse manual pode ser desenvolvido, ao criar e recriar utensílios e aparatos que se assemelham aos utilizados nas práticas institucionais originais e podem assim favorecer essa prática esportiva de forma adaptada.

Em nossa questão sobre "Você vivenciou experiências de lazer em anos anteriores ao projeto Esporte Cidadão?”, todos os alunos responderam sim. Diante disso, perguntamos em seguida para todos: "Quais foram essas experiências de lazer que você vivenciou em anos anteriores ao projeto Esporte Cidadão?”, e diversas foram as respostas. Todos os 34 entrevistados responderam que já tinham tido experiência com alguma modalidade esportiva, principalmente vivenciada dentro do âmbito escolar. Em seguida a resposta "passeio com a família" foi citada doze vezes e dentre os discursos podemos destacar:

Sempre passeio com minha família, fazemos muitas coisas juntos, sou muito ligada com minha família (Entrevistada 7).

Sou muito próximo da minha família, amamos sair e passear juntos (Entrevistada 9).

Saímos juntos em família, procuramos fazer isso sempre, principalmente quando estamos juntos (Entrevistado 21).

Os discursos mostram forte relação afetiva das famílias dos entrevistados, e esse lugar da família também é discutido nas políticas de lazer, segundo Marcellino (2008, p. 83): 
direitos humanos. É indispensável para a garantia da sobrevivência, do desenvolvimento e da proteção dos filhos e demais membros, independentemente do arranjo familiar ou da forma como vem se estruturando. É na família que se buscam os aportes afetivos e materiais necessários ao desenvolvimento e ao bem-estar dos seus componentes.

A família é decisiva na educação dos seus membros, pois nela são absorvidos os valores éticos, humanitários e culturais, sendo aprofundados os laços de afetividade e solidariedade. O lazer em família pode fortalecer os laços familiares, contribuindo para a maior sensação de conforto e segurança, tanto para os filhos quanto para o casal.

As respostas "assistir filme/TV” mencionada por onze entrevistados, "jogar vídeo game" citado por sete entrevistados, enfatizam outro tipo de aspecto como podemos observar a seguir.

Sempre gostei de assistir filmes, séries na TV, gasto até hoje um pouco tempo com isso. (Entrevistado 13)

Gostava muito de assistir TV e filmes, agora diminuiu um pouco, mas sempre gostei (Entrevistado 21).

Seis entrevistados mencionam a resposta "ler livro" como vivência de experiência de lazer, como podemos observar a seguir.

Sempre gostei de ler, independente se são livros da escola, eu gosto de ler livros (Entrevistado 5).

Eu amo ler, desde pequena fui incentivada por minha avó, que ao invés de me dar brinquedos, sempre me presenteava com livros. Eu gosto de estudar, ler sobre vários assuntos (Entrevistada 15).

Para a entrevistada 15, por exemplo, “o gostar de ler e estudar", no seu entendimento é lazer. O fato de gostar ou não gostar de qualquer coisa não irá definir se ela está vivenciando atividades no tempo disponível. Neste momento, recorremos novamente aos estudos de Marcellino (2012), sobre o lazer depender de duas categorias fundamentais: tempo e atitude. A aluna fala do estudo como atividade do contexto do lazer que pode referente ao conteúdo intelectual, a leitura nesse caso irá ampliar o conhecimento prévio da aluna. Ainda de acordo com o mesmo autor citado acima, essa 
pode ser uma contribuição para o desenvolvimento pessoal e social da aluna. Esse aspecto pode ser considerado em todas as demais atividades do contexto do lazer.

O autor ainda afirma que o tempo disponível em casa é tempo de estreitamento de relações sociais (especialmente com amigos) e de práticas manuais ditas "semiutilitárias". Algumas respostas corroboram com os estudos de Marcellino (2008) citado acima, como "aprender culinária" citada pelas entrevistadas 8 e 16; "brincar com animais" mencionado pelo entrevistado 8 e entrevistada 18; além "fazer desenhos" citado pelas entrevistadas 16,17 e pelo entrevistado 25 .

Camargo (1986) entende o lar como refúgio e aconchego, além de um "pequeno centro cultural" no qual podemos ter a disponibilidade das várias opções de atividades de lazer. Para esse autor, o tempo destinado às atividades do contexto do lazer vivido fora de casa responde a uma necessidade humana de mudança de ritmo, de paisagem e estilo de vida. Pode-se verificar essa afirmação na resposta "sair com os amigos" de oito sujeitos entrevistados, conforme podemos destacar alguns a seguir.

Sair com meus amigos, ir ao shopping, parques, enfim estar com eles (Entrevistado 1).

Sair com amigos, porque moro em chácara e não tenho muitos vizinhos e a maioria dos meus amigos mora distante, por isso sempre gostei de sair com eles (Entrevistado 22).

Fora de casa o tempo disponível é menor, mas vivido intensamente em lugares específicos - públicos e privados - como shoppings centers, parques, cinemas, teatros, casas de shows, reuniões formais e associações, clubes (MARCELLINO, 2008, p. 89). Ao perguntarmos sobre "Além de praticar esporte tem outra forma de vivenciar o lazer?" As respostas comuns foram: "sair com os familiares", "sair com os amigos" e "divertirse". Ou seja, mais uma vez o interesse social predominante em suas falas. Nessa pergunta uma aluna entrevistada trouxe um discurso diferente de todos, que está descrito a seguir. 
Fora o esporte, o lazer para mim é relaxar, é eu me desconectar do mundo (Entrevistada 16).

Após essa resposta perguntamos o que significava “o desconectar do mundo?”, e obtivemos a seguinte resposta:

\begin{abstract}
Meus pais jogaram vôlei quando jovens, e jogavam bem, eles me cobram sabe, mas eu gosto mesmo assim. Na escola recebo também muita cobrança, vestibular, essas coisas, então quando não estou no projeto, estou bem cansada e preciso relaxar, me desconectar de tudo (Entrevistada 16).
\end{abstract}

Aqui se percebe a cobrança por parte dos pais/responsáveis sobre a performance no esporte e na escola. Observando as aulas, a entrevistada participa ativamente das mesmas, tem liderança, transmite estar alegre e feliz com as atividades. Informalmente perguntamos ao professor se os pais/responsáveis dessa entrevistada costumavam acompanhar as aulas, e ele disse que não, mas que já conversou com eles por algumas ocasiões e sempre foi questionado sobre algumas coisas que acontecem em aula. $\mathrm{O}$ professor disse que a aluna entrevistada se cobra muito, e que tem trabalhado essa situação especificamente em aula, haja vista já estar no projeto há seis anos.

Esse discurso da aluna entrevistada indica a necessidade de descanso como uma das funções do lazer. Dumazedier (1976, p.32) destaca as três funções do lazer (três Ds): descanso, divertimento/recreação e entretenimento; e desenvolvimento. "O descanso libera-se da fadiga. Neste sentido, o lazer é o reparador das deteriorações físicas e nervosas provocadas pelas tensões resultantes das obrigações cotidianas e, particularmente, do trabalho". O autor coloca o descanso como uma forma de liberar as tensões do dia a dia, assim o indivíduo volta renovado para a sua jornada de trabalho ou obrigações. Seria uma forma de lazer que revigora e prepara os sujeitos para o dia seguinte.

A segunda função, do divertimento/recreação e entretenimento é vista ligada ao tédio, à vida cotidiana. A sua postura quanto a isso é da pessoa ficar sempre naquela rotina do dia a dia, sem experimentar lugares novos, atividades novas, enfim, sem novas 
experiências. Daí a busca de uma vida de complementações, de compensação e de fuga por meio de divertimento e evasão para um mundo diferente, e mesmo diverso, do enfrentado todos os dias conforme o discurso da entrevistada 16.

A terceira função é o desenvolvimento que trata da ação praticada pelo corpo, uma maior participação social e mais livre. Praticar o desenvolvimento da personalidade, as atividades que os indivíduos praticam por ser do seu gosto, por ser de livre e espontânea vontade, sem qualquer imposição da sociedade. De acordo com a visão de Dumazedier (1976), essas três funções do lazer contribuem para que os sujeitos consigam vivem de maneira equilibrada com as obrigações do dia a dia. Apesar da reconhecida importância dos estudos do autor, entendemos a visão funcionalista como insuficiente para uma mudança social efetiva, que pode ser gerada a partir do acesso dos sujeitos à valores revolucionários como o respeito à cidadania, às diferenças sociais, a solidariedade, a cooperação, dentre outros. Entendemos que a vivência desses valores somados aos três "Ds" de Dumazedier (1976) podem gerar impactos positivos na vida dos sujeitos, que poderão não somente equilibrar as atividades de obrigação com as atividades do contexto do lazer, mas também desenvolver criticidade e ter uma vida melhor, no sentido da sociabilidade e do respeito ao outro.

A pergunta central da nossa pesquisa foi: "O que significa para você as atividades de esporte e de lazer no projeto Esporte Cidadão?" Diversas foram as respostas dos entrevistados, inclusive com mais de uma resposta, dentre elas: "Aumentei meus relacionamentos" mencionada doze vezes pelos entrevistados 10,11, 28, 30 e pelas entrevistadas $3,6,14,15,18,27,32$ e 33. "Ajudou a me socializar mais" mencionada onze vezes pelos entrevistados 2, 5, 13, 21, 34 e pelas entrevistadas 9, 12, 16, 24, 31 e 33 . "Aprendi a trabalhar em equipe" mencionada oito vezes pelos entrevistados 22 e 34, e pelas entrevistadas 12, 14, 16, 18, 19 e 29. "Melhorei nos meus estudos" mencionada 
cinco vezes pelos entrevistados 1, 2, 13, 21 e pela entrevistada 15. "Melhorei minha organização e minha disciplina" mencionada quatro vezes pelos entrevistados 20 e 26 , e pelas entrevistadas 14 e 19. "Aprendi a ter mais cooperação, respeito e valor nas coisas" mencionada três vezes pelos entrevistados 4, 23 e 25. "Aprendi a lidar com as pessoas" mencionada três vezes pelos entrevistados 1 e 25 , e pela entrevistada 29.

Os entrevistados também se referem às relações que são estabelecidas com: socialização, interação, cooperação, motivação, determinação, confiança, personalidade, respeito, nunca desistir e melhora na saúde, além de relacionarem os significados das práticas aos projetos como uma oportunidade. Oportunidade de aumentar suas amizades, de aumentar e melhorar seus relacionamentos, de trabalhar em equipe e a lidar com pessoas.

Antes do vôlei eu era muito fechado, depois das aulas estou tendo a oportunidade de aprender a lidar com pessoas, pessoas que são diferentes de mim (Entrevistado 1).

As atividades do projeto me ajudam a saber lidar com as pessoas de uma forma cooperativa, ter mais paciência com as pessoas (Entrevistado 25).

Aprendo com as atividades do projeto a lidar com as diferenças, sempre tem muita gente entrando no projeto, e tem muita diferença de pessoa para pessoa (Entrevistada 29).

Percebe-se que para os entrevistados participantes do projeto Esporte Cidadão a oportunidade de aumentar os relacionamentos e de socialização foram mencionadas como principais significados atribuídos às atividades desenvolvidas no projeto.

O conteúdo social do lazer é predominante nos discursos dos sujeitos participantes do projeto. Esses interesses sociais são alcançados através da busca de contatos e do convívio social que visam, em grande parte a sociabilidade. Muitas vezes as pessoas buscam situações para ter contato com outras pessoas e momentos que favoreçam o convívio social, o encontro com sujeitos. 
Diante desse conteúdo social presente fortemente na fala dos entrevistados, podemos recorrer aos estudos de Marcellino (2001, p. 123), que diz:

o lazer é um dos maiores fenômenos da esfera da cultura responsável pela potencialização da rede de sociabilidade, em que grupos se organizam ampliando a rede de troca e sociabilidade e enriquecendo a experiência pessoal e coletiva.

Atualmente se vivencia situações de lazer, reivindicando novas formas de relacionamento social. Contudo, é nítido as mudanças em relações afetivas e nas considerações sobre o próprio corpo, almejando o contato com o belo e, sobretudo, buscando prazer (MARCELLINO, 1995).

A oportunidade de aumentar os relacionamentos e de socializar-se mais, também é percebido nos fatores comportamentais e sociais, e são citados várias vezes pelos entrevistados:

Está sendo uma fase muito importante da minha vida. As atividades do projeto estão ajudando a crescer mais, me ajudam e melhorar meu desempenho na escola. É uma coisa que alegra a minha semana, onde posso conhecer novos amigos e socializar mais (Entrevistada 12).

Antigamente eu era egoísta, eu achava que só eu sabia fazer as coisas, e com o vôlei eu pude perceber que as pessoas erram, todos erram, ninguém é perfeito, ninguém acerta toda vez. As atividades do projeto me ensinam a saber que vamos errar, mas também vamos aprender. Isso me mostra a importância do trabalho em equipe. Antes na escola só fazia trabalhos sozinhos, hoje em dia faço em grupos todas as vezes (Entrevistado 13).

Nota-se que as atividades de esporte e lazer que são desenvolvidas no projeto geram influências na educação dos participantes. O lazer como instrumento e como objeto da educação é discutido por Marcellino (2000, p. 50), onde o autor afirma que "o lazer é um veículo privilegiado de educação", e também diz que:

para a prática das atividades de lazer é necessário o aprendizado, o estímulo, a iniciação aos conteúdos culturais, que possibilitem a passagem de níveis menos elaborados, simples, para níveis mais elaborados, complexos, procurando superar o conformismo, pela criticidade e pela criatividade (MARCELLINO, 2000, p.50). 
Nesse sentido, o lazer, como veículo de educação, potencializa o desenvolvimento social e pessoal dos indivíduos, eis que além de favorecer a compreensão da realidade a partir do aumento da sensibilidade pessoal, auxilia no reconhecimento das responsabilidades sociais.

O entrevistado 1 relata a importância das atividades que realiza, projetando seu futuro a partir dela, ou seja, gerando assim a importância da contextualização para o aprendizado das pessoas.

Gosto daqui, porque gosto de conhecer e ajudar pessoas novas, no futuro acho que quero seguir com a educação física, ser professor, e o que eu faço hoje me ajuda muito nisso. Quando entra um aluno novo é legal ensinar os fundamentos, gosto de ajudar as pessoas (Entrevistado 1).

Para oito sujeitos entrevistados, as atividades do projeto auxiliam no aprendizado para trabalhar em equipe, sendo que quatro desses sujeitos (entrevistados 20 e 26, e entrevistadas 14 e 19) relataram também melhora na organização e disciplina, como estão descritos a seguir.

As atividades do projeto ajudam a me organizar melhor, porque preciso dividir melhor meu tempo para as coisas, além de ajudar a trabalhar em equipe e melhorar minha disciplina também (Entrevistada 14).

No projeto eu aprendo muito a trabalhar em equipe, a ter disciplina, ajudar ao próximo, porque temos que ter paciência com algumas pessoas (Entrevistada 19).

Antes de eu entrar no projeto eu falava muito palavrão, agora estou maneirando, estou me disciplinando e aprendendo a trabalhar em equipe (Entrevistado 20).

Eu aprendi no basquete a ter disciplina, a respeitar os outros e saber que nem tudo o que a gente faz é por querer, além de saber perder (Entrevistado 26).

O desenvolvimento do conceito do trabalho em equipe, da disciplina, da cooperação pelas atividades de esporte e de lazer propostas pelo projeto podem ser considerados objetos de educação nesse processo também. Tratando-se do lazer como veículo de educação, é necessário considerar suas potencialidades para o desenvolvimento pessoal e social dos indivíduos. Tanto cumprindo objetivos 
consumatórios, como o relaxamento e o prazer propiciados pela prática ou pela contemplação, quanto objetivos instrumentais, no sentido de contribuir para a compreensão da realidade.

As atividades de lazer favorecem, a par do desenvolvimento pessoal, também o desenvolvimento social, pelo reconhecimento das responsabilidades sociais, a partir do aguçamento da sensibilidade ao nível pessoal, pelo incentivo ao auto-aperfeiçoamento, pelas oportunidades de contatos primários e de desenvolvimento de sentimentos de solidariedade (MARCELLINO, 2007).

Percebe-se que no discurso dos entrevistados 20 e 26, que as atividades de esporte e lazer do projeto contribuem também para uma transformação social nos sujeitos. Com relação a essa transformação, Marcellino (2001, p. 158-159) diz:

[...] o lazer é emblemático, pois assim como pode ser um produto de consumo, pode ser um elemento 'revolucionário'. O lazer agrega, reúne pessoas, busca identidades. Retira as pessoas de dentro das casas onde estão presas pela insegurança e devolve-as ao convívio social em que há conhecimento, troca, afeto e também questionamentos, consciência e rebeldia.

As atividades de esporte e lazer do projeto podem ser consideradas frutos de relações sociais, além de um espaço de vivência cultural no tempo disponível das obrigações profissionais, escolares, familiares e sociais.

O discurso da entrevistada 27 traz elementos significativos nas relações sociais vivenciadas nas atividades do projeto:

A minha maior motivação é estar aqui entre amigos, nossa união, todos são muito amigos aqui, o ambiente é muito gostoso. Eu não consigo encontrar esse ambiente em nenhum outro lugar, somente aqui nas aulas (Entrevistada 27).

Percebe-se que há satisfação dos alunos entrevistados na participação das atividades do projeto. Ter como referência a participação no que se refere ao poder de decisão, evidencia-se o desenvolvimento do modelo de administração participativa na relação com a população, vendo-a como parceira do Estado e incentivando o surgimento 
de sujeitos políticos coletivos, representados amplamente pelos movimentos populares. (STIGGER, 1998).

Corroborando com a afirmação acima, uma obra da pesquisa bibliográfica intitulada "Percepção da qualidade do ambiente e vivências em espaços públicos de lazer", de autoria de Emília Silva e colaboradores, publicada no ano de 2016, chama a atenção para a importância da identificação dos interesses dos frequentadores, a fim de que os projetos sejam executados a partir dos anseios da população.

Depoimentos como do entrevistado 5 nos revelam o interesse físicoesportivo das atividades do projeto: "Eu gosto de fazer aulas aqui, eu gosto do projeto, quero aprender coisas novas, quero melhorar meu jogo de basquete".Já o discurso da entrevistada 16 nos mostra o interesse social pelas atividades do projeto: "Venho aqui principalmente para encontrar meus amigos de equipe, interagir com eles, saber como estão. Damos muitas risadas, conversamos bastante e claro jogamos juntos".

A melhora da saúde como significado das atividades do projeto foi citada por somente dois sujeitos entrevistados (17 e 22), diferente dos dados da pergunta sobre "o que é esporte para você?", onde a saúde foi a palavra mais citada.

As atividades do projeto têm ajudado no meu porte físico, pois desde criança tive obesidade e eu tenho melhorado com as aulas (Entrevistado 17).

A escolha pelo basquete para mim é o que mais deu resultado. Eu estava pesando $77 \mathrm{Kg}$ e agora estou com $66 \mathrm{Kg}$. Antigamente tinha muitas dores nos pés e braços, e agora não sinto isso, eu me sinto mais livre, ágil para fazer as coisas (Entrevistado 22).

Podemos perceber na fala desses entrevistados, que entendem a prática do esporte como meio de evitar o sedentarismo e a obesidade, dentre outras funções. E, por fim, a última pergunta aos alunos entrevistados - "O que faz com que você participe/permaneça no projeto?" - diversas foram as respostas. Dentre as respostas as mais citadas foram: "porque eu gosto muito" mencionada ao total nove vezes, sendo três pelos entrevistados 
$5,13,25$, e seis pelas entrevistadas $6,7,8,9,14$ e 24 . A resposta "porque eu preciso melhorar minha saúde" foi mencionada oito vezes, sendo três pelos entrevistados 10,11 , 23, e cinco pelas entrevistadas 12, 15, 17, 18 e 24. "Oportunidade de encontrar os amigos” foi a resposta mencionada sete vezes, sendo quatro pelos entrevistados $20,21,28,30$, e três pelas entrevistadas 27, 32 e 33. A resposta "quero melhorar meu jogo" foi mencionada seis vezes, sendo cinco pelos entrevistados $2,4,20,22$, 26, e uma pela entrevistada 31. "a atenção dada pelos professores" foi a resposta mencionada quatro vezes, pelas entrevistadas 16, 19, 27 e 29.

Apesar da resposta "porque eu gosto muito" ser mencionada várias vezes, inúmeros foram os motivos dos sujeitos entrevistados conforme as descrições a seguir.

Quando venho na aula de vôlei meu dia fica mais leve, eu encontro meus amigos e faço aquilo que eu gosto (Entrevistada 7).

As atividades do projeto me ajudaram a ter novas perspectivas para eu fazer coisas que eu goste (Entrevistada 8).

Antes eu não gostava tanto de assim do basquete, mas depois que comecei a frequentar gostei bastante, passei a me interessar mais, o ambiente é legal e gostoso (Entrevistado 25).

Percebe-se que vários são os motivos que fazem com que os alunos permaneçam nas atividades do projeto. Em conversa informal com um dos professores, ele relatou que principalmente os alunos adolescentes sempre o procuram para contar seus objetivos e o que pretendem com as aulas. $\mathrm{O}$ professor disse que fazem muita menção às coisas do passado e querem sempre novos desafios.

Gerar relacionamentos, amizades e fazer parte de um grupo foram base para a resposta: "oportunidade de encontrar com os amigos", segundo os relatos a seguir.

Eu tenho uma maior convivência com outras pessoas, aprendo com as diferenças, que cada um tem o seu tempo, e a medida do tempo você vai observando que as pessoas vão te acolher. O projeto tem muito disso, o de acolher as pessoas, além do que me divirto muito aqui (Entrevistada 33). 
A minha maior motivação para estar no projeto é a união, todos são muito amigos, o professor é muito bom, o ambiente é gostoso, além de ser de graça ... é perfeito (Entrevistada 27).

Meus amigos é o que mais motiva a estar vindo às aulas do projeto (Entrevistado 20).

Observamos ao longo das aulas, que os alunos em sua maioria chegam ao CET em grupos. Em conversa informal, eles disseram que combinam um horário, seja na escola porque estudam juntos ou por morarem próximos uns dos outros. Aqueles que não conseguiam ir em grupo, se reuniam na quadra de peteca.

Alunos das modalidades basquete, vôlei, atletismo e futebol se reúnem nesta quadra de peteca, onde tornou-se um ponto de encontro. Eles chegam aos poucos, se cumprimentam, conversam e logo um dos alunos chega com uma bola de vôlei concedida pelo professor, e se organizam para um jogo sem muitas regras na quadra de peteca, que possui rede e marcações. Uma situação interessante é que nesse momento independente da modalidade que estão inscritos no projeto, os alunos estão juntos, conversando e jogando vôlei.

Os interesses sociais do lazer podem encontrar seu campo de satisfação nesses pontos de encontro. Os pontos de encontro manifestam-se de formas diferenciadas, variando de acordo com as características gerais da sociedade (MARCELLINO, 2000, p. 92).

Na nossa observação, nesse "ponto de encontro" (quadra de peteca) percebemos que apesar de serem alunos de modalidades esportivas diferentes, estudantes de escolas distintas, os sujeitos participantes ao se reunirem tratam de coisas em comum. Essas variadas formas de "associativismo informal", propiciadas pela vivência do lazer, geralmente não são registradas em estatísticas e devem ser estudadas, segundo Marcellino (2000, p. 93). O mesmo autor cita Paulo de Salles Oliveira que afirma: 
[...] torna-se, então [...] extremamente importante considerar a presença dos grupos de encontro, a reunir pessoas com problemas comuns, que se unem a fim de encontrar apoio mútuo e soluções para resolver seus problemas. Tratase de uma atividade característica dos interesses sociais no lazer, que revela facetas pouco conhecidas dentro associativismo [...].

Outro ponto importante observado nos depoimentos são os laços de amizade que são adquiridos e fortalecidos ao longo do projeto.

As atividades do projeto ajudam a minha saúde, mas principalmente tem me ajudado com minha timidez. Eu sempre quis fazer o vôlei e eu não conhecia ninguém e eu morria de vergonha. Uma amiga que já fazia o vôlei me convidou a vim para o projeto, e nas conversas antes da aula lá na quadra de peteca, nas atividades nas aulas eu comecei a me soltar, até porque o professor pedia para fazer exercícios em duplas ou trios (Entrevistada 27).

Quando os alunos entrevistados atribuem à importância das atividades do projeto e trazem com eles elementos como: laços de amizade, alunos que se tornam mais comunicativos, mais participativos, isso contribui e favorece ao desenvolvimento social no ambiente de aula. De acordo com Kunz (1994), para a formação de "sujeitos livres e emancipados" é necessário que o desenvolvimento do esporte supere as formas tradicionais de ensinar e praticar o esporte, na busca da autonomia e da interação social dos sujeitos.

Notamos que realmente os interesses dos alunos estão nas relações que são estabelecidas com outros alunos. A possibilidade de conhecer novas pessoas, estabelecer novos contatos fica ainda mais evidente nas declarações dos alunos nas entrevistas. Isso mostra que para os alunos apenas o fato de fazer a aula não é tão atrativo para eles, outros fatores como socializar-se, competir, parecem ser mais interessantes. O desejo dos alunos em jogar está relacionado ao interesse social do lazer. Os interesses sociais são alcançados por meio da busca de contatos e do convívio social que visam, em grande parte a sociabilidade. Muitas vezes as pessoas buscam situações para ter contato com outras pessoas e momentos que favoreçam o convívio social, o encontro com sujeitos. Em tempos de tecnologia, muitos destes encontros e o convívio social ocorrem 
principalmente através das redes sociais de modo virtual o que tem afastado as pessoas dos encontros presenciais. Esse é o fato atual sem questionamentos da negatividade ou positividade destas relações virtuais.

As práticas esportivas podem ser um aglutinador de pessoas que procuram estes encontros presenciais de convívio com o outro. Podemos neste momento relacionar os resultados da nossa pesquisa com a obra da pesquisa bibliográfica intitulada "Os significados dos projetos de esporte e lazer para alunos do Instituto Federal do Norte de Minas Gerais", de Santos e Silva (2018), onde a maioria dos alunos entrevistados na pesquisa afirmam que os projetos de esporte e lazer são importantes em suas vidas pelo fator da oportunidade de socialização, competição e pela diversão, ou seja, além da vivência do esporte e lazer de forma compensatória, os projetos do campus Januária também contribuem com a construção de valores e sentidos na vida dos sujeitos participantes. Assim como para os sujeitos entrevistados participantes do projeto Esporte Cidadão, os entrevistados participantes dos projetos de esporte e lazer do IFNMG Campus Januária, a saúde, o lazer e as oportunidades de socialização foram mencionados como principais significados atribuídos às práticas oferecidas nos projetos.

Com relação ao interesse social do lazer os resultados dessa pesquisa e a da mencionada acima, são semelhantes. Os significados das atividades de esporte e lazer realizadas pelos alunos entrevistados das pesquisas evidenciam isso, afirmando que os mesmos são importantes em suas vidas, pois são as diversas oportunidades e possibilidades de socialização, de divertimento, descanso e aprendizagem, ou seja, os alunos entendem que os projetos contemplam o descanso, o divertimento e o desenvolvimento pessoal e social. As duas pesquisas se aproximam em seus resultados quando os entrevistados falam da socialização, da integração, do esporte ser um caminho 
mais curto para estreitar as relações, o sentido que ambas dão à prática do esporte de aprovar e valorizar os projetos de esporte e lazer desenvolvidos.

De uma forma geral podemos dizer que as atividades do projeto Esporte Cidadão pelos depoimentos dos seus frequentadores, oferecem oportunidade para a socialização, competição e diversão de seus participantes.

Podemos relacionar essas respostas com os resultados da pesquisa bibliográfica intitulada "Representações sociais dos participantes de projeto esportivo de Vitória", de Mello et al. (2018), onde retratam que o esporte e o lazer podem contribuir na construção de sentidos, que podem estar vinculados “ao jogar” e que estão relacionados com a amizade, o aprender das modalidades esportivas, a estética/saúde, a ascensão social e novas perspectivas de vida, no caso dos adolescentes e jovens. Esses sentidos foram construídos por meio de experiências que os adolescentes e jovens estabelecem com as atividades esportivas mediadas pelos projetos de esporte e lazer, e que se materializam em diferentes figuras do aprender.

"Esporte para mim é uma forma de lazer, uma atividade que tem regras, é oportunidade e é um direito da população" (Entrevistado 11).Sobre a população exercer o direito às oportunidades que o lazer e o esporte proporciona, segundo o relato do entrevistado 11, as duas obras da pesquisa bibliográfica dos autores Borges (2017) e Lopes; Santos; Isayama (2016), concluem que o lazer não vem sendo tratado, de fato, como um direito social atrelado a sua garantia e sim às necessidades de outros direitos. Os autores também apontam que o esporte e o lazer têm a propriedade de favorecer o crescimento pessoal, crítico e criativo, assim como a prioridade de formação à cidadania. Outra obra da pesquisa bibliográfica de Athayde e Passos (2018), traz alguns resultados que corroboram com o discurso do entrevistado 11. Os autores dizem que a cidadania não deveria ser o objetivo maior da educação (como se ela fosse sinônimo de 
liberdade efetiva e plena), mas sim da emancipação humana, que é efetivamente sinônimo de liberdade plena. Nesse sentido, não se colocam contra a relação entre cidadania e educação, mas delimitam de modo claro que a cidadania deve ser um meio e não o fim desse processo.

As falas dos entrevistados da pesquisa indicam que o projeto Esporte Cidadão de Indaiatuba-SP contribui para a mediação de conhecimentos e de valores e para a produção de significados por parte de seus frequentadores, colaborando para que os sujeitos apropriam-se de uma visão mais crítica da realidade em que estão inseridos, exercitando sua capacidade de atribuir sentidos, desenvolver ações cooperativas, podendo produzir mudanças em suas vidas.

\section{Considerações Finais}

Políticas públicas de esporte e lazer como o Projeto Esporte Cidadão de Indaiatuba-SP devem ser idealizadas, elaboradas, administradas e avaliadas continuamente sob a perspectiva intersetorial, sendo consolidada a partir de uma visão crítica e teórico-técnica acerca das necessidades dos beneficiários como uma política abrangente, sob responsabilidade e fiscalização dos gestores e da sociedade como aliada. Esse estudo vai ao encontro do que afirma Marcellino (2012) sobre a necessidade de contribuição para ampliar os conceitos de lazer e esporte do projeto, com a intencionalidade de que as práticas desenvolvidas gerem pessoas mais críticas, autônomas e reflexivas, tendo como base argumentos e fundamentos para a formação e transformação da sociedade.

Podemos destacar alguns pontos importantes como resultados de nossa pesquisa. Com relação ao entendimento sobre esporte, os sujeitos entrevistados o associam aos benefícios a saúde, lazer, felicidade, trabalhar em equipe e competição. 
Com relação ao entendimento sobre lazer, os interesses mais vinculados nos discursos dos entrevistados, são os interesses sociais, além dos conteúdos físico esportivos e os interesses prático/manuais.

Percebe-se que os sujeitos possuem interesses pessoais para suprir suas necessidades de diversão, descanso e lazer. Para a maioria dos entrevistados os interesses sociais do lazer estão mais presentes, haja vista que atribuem significados às atividades que realizam com forte conteúdo de sociabilidade, expresso no contato com as pessoas.

Os significados que os alunos entrevistados atribuem às atividades do projeto se remetem à procura de relacionamentos, de querer socializar-se mais, buscar novas amizades, conseguir trabalhar em equipe e saber lidar com pessoas. Os interesses sociais são alcançados por meio da busca de contatos e do convívio social que visam, em grande parte, a sociabilidade. Muitas vezes as pessoas buscam situações para ter contato com outras pessoas e momentos que favoreçam o convívio social, o encontro com sujeitos. Em tempos de tecnologia, muitos destes encontros e o convívio social ocorrem principalmente por meio das redes sociais de modo virtual o que tem afastado as pessoas dos encontros presenciais. Esse é o fato atual sem questionamentos da negatividade ou positividade destas relações virtuais. As práticas esportivas podem ser uma opção de reunir pessoas que procuram estes encontros presenciais de convívio com o outro.

Todas as atividades desenvolvidas no projeto Esporte Cidadão são consideradas atividades do contexto do lazer, os alunos demonstram construir novos elementos e conhecimentos a partir dessa experiência. A questão da sociabilidade é a que mais se destaca, dentre outros conteúdos do lazer como o físicoesportivo, o prático-manual e o intelectual, também são citadas.

A partir dos dados apresentados até então, gostaríamos agora de tecer algumas considerações: (1) Ainda que os projetos de esporte e lazer sejam percebidos como 
espaços que propiciem uma socialização positiva, necessita-se considerar a complexidade envolvida no processo de incorporação de comportamentos e valores. Os projetos de esporte e lazer são apenas um dentre vários espaços socializadores onde crianças e adolescentes normalmente se inserem. (2) Ainda que os projetos de esporte e lazer sejam apontados como espaços educativos, necessita-se considerar as diferentes visões e expectativas dos agentes em relação às aprendizagens promovidas pelos projetos. Tais visões podem interferir tanto positivamente quanto negativamente nestas aprendizagens. (3) Ainda que a participação nos projetos de esporte e lazer nem sempre depende da vontade e escolha de determinadas crianças e adolescentes, suas expectativas e interesses precisam ser consideradas nas propostas. (4) É fundamental os gestores terem um olhar mais profundo dos valores e significados que são atribuídos pelos alunos aos projetos de esporte e lazer, para conhecerem as motivações, as expectativas e as necessidades dos sujeitos participantes.

Faz-se necessário que os gestores do projeto Esporte Cidadão tenham um olhar mais profundo dos valores que são atribuídos pelos alunos para que cada vez mais um número maior de alunos se sinta valorizado em participar das atividades do projeto. A importância desse olhar pelos gestores vai ao encontro dos estudos de Marcellino (2001, p. 162), em que o autor afirma que é preciso refletir e agir em consonância com a realidade. "É necessário comprometer-se com a solidariedade, com a humanização, dentro de um contexto histórico-social. Se faz importante ampliar os conhecimentos, substituindo uma visão ingênua da realidade por uma visão crítica, desafiando a não serem neutros ante o mundo".

Estudos futuros poderão ter como foco outros núcleos que fazem parte do Projeto Esporte Cidadão de Indaiatuba-SP e que não fizeram parte do escopo desta pesquisa. Mais estudos, realizados em outras localidades, também são necessários a fim de se entender 
os significados atribuídos a projetos de esporte e lazer. A compreensão que diferentes agentes envolvidos com esses projetos possuem do mesmo pode contribuir para com um melhor planejamento das ações desenvolvidas, bem como para o desenvolvimento de políticas públicas e programas que atendam as necessidades e interesses da população.

\section{REFERÊNCIAS}

ATHAYDE, P., PASSOS, F. Esporte e políticas públicas sociais no Brasil: uma discussão sobre cidadania e emancipação humana. Pensar a Prática, Goiânia, v. 21, n. 3, jul./set. 2018.

BORGES, C.N.F. Educação cidadã pelo lazer: a contribuição das políticas públicas de esporte e lazer. Licere, Belo Horizonte, v.20, n.1, mar/2017. DOI: https://doi.org/10.35699/1981-3171.2017.1599

CAMARGO, L. O. de L. O que é lazer. São Paulo: Brasiliense, 1986.

DUARTE, R. Pesquisa Qualitativa: Reflexões sobre o Trabalho de Campo. Cadernos de Pesquisa, São Paulo, n. 115, p. 139-154, março/2002.

DUMAZEDIER, J. Lazer e Cultura Popular. São Paulo: Perspectiva, 1976.

GEERTZ, C. A interpretação das culturas. Rio de Janeiro: LTC, 1989.

HELAL, R. O que é Sociologia do Esporte. São Paulo: Brasiliense, 1990.

KUNZ, E. Transformação didático-pedagógica do esporte. Ijuí: Editora Unijuí, 1994.

LOPES, T. B.; SANTOS, D. C. S. dos; ISAYAMA, H. F. Reflexões sobre política social e a política de lazer no Brasil. Licere, Belo Horizonte, v.19, n.3, set/2016. DOI: https://doi.org/10.35699/1981-3171.2016.1297

MARCELLINO, N. C. Lazer e Educação. 3. ed. Campinas: Papirus, 1995 2000.

Estudos do lazer: uma introdução. 2. ed., ampl. Campinas: Autores Associados,

(org.) Formação e Desenvolvimento de pessoal em lazer e esporte. Campinas: Papirus, 2001.

Algumas aproximações entre lazer e sociedade. Animador Sociocultural:

Revista Iberoamericana Lazer e Sociedade. Rio de Janeiro, 2007.

Lazer e sociedade: múltiplas relações. Campinas: Alínea, 2008.

Estudos do lazer: uma introdução. 5. ed. Campinas: Autores Associados, 2012. 
MELLO, A. S.; SILVA, J. S. S.; JORGE, R. S.; SCHNEIDER, O.; SANTOS, W. dos. Representações sociais dos participantes de projeto esportivo de Vitória. Movimento, Porto Alegre, v. 24, n. 2, p. 399-412, abr./jun. de 2018.

MINAYO, M. C. de S. Ciência, técnica e arte: o desafio da pesquisa social. Petrópolis: Vozes, 1994.

SANTOS, R. F. dos; SILVA, C. L. da. Os significados dos projetos de esporte e lazer para os alunos do Instituto Federal do Norte de Minas Gerais. Licere, Belo Horizonte, v.21, n.1, mar/2018. DOI: https://doi.org/10.35699/1981-3171.2018.1777

SEVERINO, A. J. Metodologia do Trabalho Científico. São Paulo: Editora Cortez, 2007.

SILVA, E. A. P. C. da, et al. Percepção da qualidade do ambiente e vivências em espaços públicos de lazer.Rev. Bras. Ciênc. Esporte, Brasília, UnB, v. 38, n. 3, p. 251-258, 2016.

STIGGER, M. P. Políticas sociais em lazer, esportes e participação: uma questão de acesso e de poder; ou subsídios para tomar uma posição frente a pergunta: "são as políticas públicas para educação física, esportes e lazer, efetivamente e políticas sociais”? Motrivivência. v.10, n. 1, 1998.

TUBINO, M. J. G. O que é esporte: uma enciclopédia crítica. Coleção primeiros passos. 2. ed. São Paulo: Brasiliense, 1999. v. 276.

VELOZO, E. L. Cultura de movimento e identidade: a educação física na contemporaneidade. Tese (Doutorado em Educação Física). Faculdade de Educação Física, Universidade Estadual de Campinas - Campinas, SP: [s.n], 2009.

\section{Endereço dos Autores:}

Luiz Guilherme Bergamo

Centro Universitário Max Planck (UniMAX)

Av. Nove de Dezembro, 460 - Jardim Pedroso

Indaiatuba - SP - 13.343-060

Endereço Eletrônico: guibergamo@ hotmail.com

Cinthia Lopes da Silva

Universidade Metodista de Piracicaba

Secretaria do Programa de Pós-Graduação em Ciências do Movimento Humano

Rodovia do Açúcar, km 156 (SP-308), n. 7000 - Bloco 7

Piracicaba - SP - 13.423-170

Endereço Eletrônico: cinthialsilva@uol.com.br 